\title{
Hyaluronsäure bei Falten ist für Kosmetikerin tabu
}

\author{
Kosmetikerinnen dürfen keine Faltenunterspritzung mit \\ Hyaluronsäure durchführen. Das hat das Oberlandesgericht \\ (OLG) in Karlsruhe entschieden.
}

Klägerin war die Betreiberin eines Zentrums für ästhetische Medizin, in dem Ärzte ebenfalls Hyaluron-Unterspritzungen anbieten. In der Nähe des Zentrums betreibt die Kosmetikerin zwei Studios.

Der Antrag der Klägerin auf Erlass einer einstweiligen Verfügung beim Landgericht Konstanz war zunächst erfolglos.

In der Berufung am Oberlandesgericht Karlsruhe wurde der Kosmetikerin definitiv untersagt, ohne behördliche Erlaubnis Faltenunterspritzungen mit hyaluronsäurehaltigen Mitteln vorzunehmen, anzubieten oder zu bewerben. Die Entscheidung ist rechtskräftig.

Nach Auffassung des Gerichts stellt die Behandlung eine erlaubnispflichtige Ausübung der Heilkunde im Sinne des Heilpraktikergesetzes dar.

Eine erlaubnispflichtige Ausübung der Heilkunde sei stets dann gegeben, wenn die Tätigkeit ärztliche oder medizinische Fachkenntnisse erfordere und die Behandlung gesundheitliche Schäden in einem nicht nur unbeträchtlichen Ausmaß verursachen könne.

Dass die Beklagte private Schulungen zur Faltenunterspritzung besucht habe und Therapien mit hyaluronhaltigen
Mitteln seit 2003 ohne Probleme durchführe, ist dem OLG zufolge nicht zu berücksichtigen.

(Martin Wortmann)

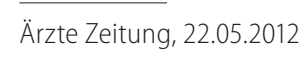

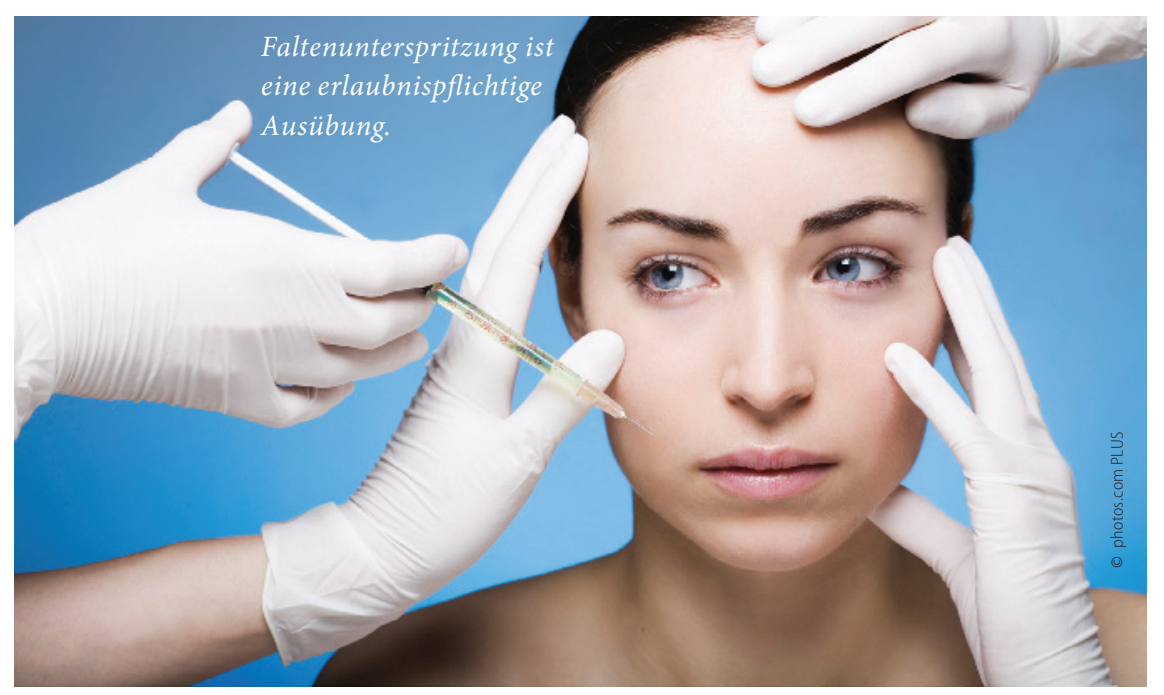

» in ihren Praxen sehr hoch sei. Beim Thema Händehygiene sagen das sogar über $50 \%$ von sich. Für die Umfrage hat die Stiftung Gesundheit die Antworten von 290 - per Zufallsstichprobe ausgewählten - Ärzten und Zahnärzten ausgewertet. Dabei zeigte sich, dass das Thema Hygiene in den Praxen durchaus eine wichtige Rolle spielt.

Rund ein Viertel der Praxen führt regelmäßig spezifische Hygiene-Leistungen wie die Erregerbestimmung bei der Wundversorgung durch. Ein weiteres Drittel hat zumindest gelegentlich mit solchen Leistungen zu tun. Und auch das Hygienegesetz, das seit Juli 2011 in Kraft ist, kennen $80 \%$ der befragten Ärzte und Zahnärzte. $45 \%$ halten das Gesetz auch für bedeutsam im Praxisalltag.

Allerdings geben nur 6\% der Ärzte an, dass das Gesetz zu wesentlichen Änderungen im Praxisablauf geführt hat. Das müsse angesichts der ebenfalls von den Ärzten selbst konstatierten „verbesse- rungswürdigen Hygienesituation als unbefriedigend angesehen werden", schreiben die Studienautoren. Dass es zum Teil noch an konkreten Verbesserungsmaßnahmen mangelt, lässt sich aber auch an einer anderen Antwort ablesen: Über die Hälfte der Umfrageteilnehmer sehen in Sachen Hygiene weder einen Weiterbildungsnoch sonstigen Handlungsbedarf.

Gerade einmal 13,6\% geben an, dass es sinnvoll sei, Maßnahmen zum Ausbau eines Risikomanagements in ihrer Praxis zu ergreifen.

\section{Hygiene-Berater kamen \\ in jede sechste Praxis}

Jeweils rund ein Fünftel der befragten Ärzte und Zahnärzte geben aber auch an, dass sie einen Fortbildungsbedarf in ihrer Praxis beziehungsweise einen Bedarf für Qualitätsnetzwerke mit anderen Niedergelassenen und Kliniken sehen. Überraschend ist, dass jede sechste Praxis schon einmal die Dienste eines externen Hygiene-Beraters in Anspruch genommen hat. Für die Kosten einer solchen Beratung müssen die Praxen nämlich selbst aufkommen. Und die Beratung ist für die Praxen nicht verpflichtend.

\section{Wer soll das Thema Hygiene im} ambulanten Bereich voranbringen?

Bei der Frage, wer das Thema Hygiene im ambulanten Bereich voranbringen soll, sprach sich die Hälfte der Praxen für die Ärztekammern aus. KVen, Fachgesellschaften und Robert Koch-Institut stehen gemeinsam (mit je rund 30\%) auf Rang zwei.

Für die Landesgesundheitsämter sprachen sich hingegen nur 16\% der Ärzte aus. Das liege wohl am schlechten Image, das die Ämter bei vielen niedergelassenen Ärzten hätten, mutmaßen die Autoren.

(Rebekka Höhl)

Ärzte Zeitung, 07.05.2012 